\title{
Novel Procedure; Roux en Y Gastric Bypass as a Definit Treatment of Leak after sleeve Gastrectomy
}

\author{
Imran Abbas $\mathrm{S}^{1 *}$ and Pazouki $\mathrm{AR}^{2}$ \\ ${ }^{1}$ Department of Minimal Invasive Surgery, Rasoul Akram Hospital, Iran \\ ${ }^{2}$ Department of Bariatric Surgery, Iranian Hospital, Dubai
}

Submission: December 20, 2016; Published: January 25, 2017

*Corresponding author: Imran Abbas MD, Laparoscopic Bariatric Surgeon, Dubai Health Authority, Dubai, Tel: 00971558038573;

Email: dubaiobesity@gmail.com

Keywords: Sleeve gastrectomy; Roux en Y gastric bypass leak; Fistula; Restrictive surgery

\section{Introduction}

Bariatric surgery has different types and the most common restrive type of bariatric is Laparoscopic Sleeve gastrectomy [14]. The most common place of leak after sleeve gastrectomy is at the esophageal-gastric junction, contained leaks are usually treated by coated self-expending stents, Fibrin sealing glues, coils, percutaneous pigtil drainage [5,6]. In some patients chronic fistulas need total gastrectomy [7].

The technique of laparoscopic sleeve gastrectomy has been standarized and some controversies exist regarding the sleeve volume, coverage of the staple line, bougie used to size the sleeve, extention of the antral resection and so forth [1,2]. In our LGS procedure, the bougie is $36 \mathrm{~F}$ in diameter, the antrum is resected $4 \mathrm{~cm}$ from pylorus using 1 st green $45 \mathrm{~mm}$ and than 5 blue $60 \mathrm{~mm}$ long cartridges sequentially. We also enforse the stapler line with PDS 2-0 seroserosal continous Lambert sutures, intraoperative leak test was done by irrigating the sleeve with methylene blue and obstructing the duodenum outlet until the dye is seen at mouth, usually with less than $60 \mathrm{ml}$. A patzer drain is positioned along the staple line. A gastrografin swallow test has been done within the first 24 hours postoperatively. We consider both tests, the oral dye and gastrografin study, to be complementary tests for leakage.

\section{Case Report}

A 37 years old man, with BMI of $48 \mathrm{~kg} / \mathrm{m} 2$, had been undergone LSG on 5th Jan, 2016 without incident. The leak tests were negative; however, he was readmitted on the 5 th postoperative day with fever, chills, and leukocytosis. Abdominal CT scan with contrast was normal but gastrografin study has confirmed leak at the esophagogastric junction. Patient has been reoperated laparoscopically, lot of secretion were present near the EGJ and has been suctioned and irrigated. A feeding tube jejunostomy has been done $50 \mathrm{~cm}$ distal to trietz ligament and the leak place has been drained with a patzer large size drain. Broad spectrum antibiotics have been started and patient vital sign has been stabled after $12 \mathrm{hrs}$.

After 24 hours of surgery feeding tube jejunostomy has been checked with gastrografin study that was normal and clear liquid diet has been started. We also start drinking water the day after surgery that has been completely drained by drain. Patient has been discharged at the 3rd day of surgery. Patient has been under close observation and also his upper endoscopy has been done after one month of surgery, endoscope easily had access to deudenum but fleuroscpic study confirmed distal obstruction that was due gastric pouch twist. Patient routinely drinked water that has been drained in drain.

High calorie liquid diet and multivitamins has been gavaged by feeding tube jejunostomy. Patient has been observed for three months but he never tolerated liquid diet per mouth. After three months we decided to change sleeve to Roux en Y gastric bypass. Laparoscopically we had explored the abdomin and faced lot of adhesions, after adhesionolysis we have confirmed the leak tract. Below leak tract we transversely cut the gastric pouch with green cartridge with $60 \mathrm{~mm}$ length. We separate the jejunal limb from abdominal wall that has been used for feeding tube jejunostomy that was $50 \mathrm{~cm}$ distal to trietz ligament.

The efferent limb has been anastomosed to gastric pouch by hand sewen method in two layers and afferent limb anastomosis (jejunojejonostomy) has been done $100 \mathrm{~cm}$ distal to gastrojejunostomy. After air leak test and methylene blue leak test a carrogate drain has been placed under gastrojejunostomy 
and patzer drain remain in leak region. At the $1^{\text {st }}$ day after surgery gastrografin study was normal and clear liquid diet has been started orally. There was no secretions in patzer drain that has been place in leak area and patient has tolerated liquid diet. Patient has been discharged at the 3rd day of surgery and there was no secretion in drain and after one week of definite surgery both drains has been removed [8].

\section{Discussion}

The SG was first described as a parietal gastrectomy by Marceau et al. [9] in 1993 as the first part of the duodenal switch; however, the use of the isolated SG technique is more recent. We have used the isolated LSG operation [3]: in patients with a low BMI of $40-50 \mathrm{~kg} / \mathrm{m}^{2}$ [1]; Leak etiology In our patients, if a LSG leak occurs, the most common site is at the end of the upper staple line, in the EGJ [4]. It might be the most likely site because of the high intragastric pressure in a narrow and long cavity (35 cm long), with low compliance and probable immediate stasis after surgery. Vascular ischemia is unlikely, because all the lesser curvature vessels have been preserved [10].

Treatment Once the leak has been diagnosed, if no sepsis is present, conservative management is indicated with antibiotics, percutaneous drainage of any collections, enteral nutrition with a silicone tube (guided by the interventional radiologist) distal to the duodenum (safer and cheaper than total parenteral nutrition), frequent computed tomography scans, and daily clinical evaluation until the leak is considered healed by negative findings on the leak tests. Some patients have required total gastrectomy with good results, but it is a more aggressive technique than the Roux limb [6].

The Roux limb should provide better compliance because allows for better drainage than a sleeve, which can have possible functional disorders or stenotic areas. LSG is not an easy procedure and, until it becomes standardized, is still a "surgeondependent technique," because a range complications can occur from leaks (more likely in low-volume pouches) to insufficient weight loss (high-volume pouches) that will need a resleeve operation [11] or completion of the duodenal switch. To date, during a follow-up of 6 months for our patient, no secondary effects have developed with this Roux en $\mathrm{Y}$ gastric bypass operation, and his weight loss was not affected. True, the patients now has restrictive operation, the Roux-en-Y gastric bypass.

\section{Conclusion}

We have reported on our short experience of only one patient to treat a complication of the EGJ fistula with a Roux en $\mathrm{Y}$ gastric bypass as a definite treatment for the increasingly popular LSG procedure leakage. Disclosures The authors claim no commercial associations that might be a conflict of interest in relation to this article.

\section{References}

1. (2007) Clinical Issues Committee of the American Society for Metabolic and Bariatric Surgery Position statement: sleeve gastrectomy as a bariatric procedure. Surg Obes Relat Dis 3: 573-662.

2. Baltasar A, Carlos Serra MD, Marcelo Bengochea MD, Rafael Bou MD, Luis Andreo MD (2008) Surgery for Obesity and Related Diseases 4(2008): 759-763.

3. Deitel M, Ros C, Gagner M (2008) The First International Consensus Summit for Sleeve Gastrectomy (SG), New York City, October 25-27, 2007. Obes Surg 18(5): 487-496.

4. Baltasar A, Serra C, Pérez N, Bou R, Bengochea M, et al. (2005) Laparoscopic sleeve gastrectomy: a multipurpose bariatric operation. Obes Surg 15(8): 1124-1128.

5. Salinas A, Baptista A, Santiago E, Antor M, Salinas H (2006) Selfexpanding metal stents to treat gastric leaks. Surg Obes Related Dis 2(5): 570-572.

6. Serra C, Baltasar A, Andreo L, Pérez N, Bou R, et al. (2007) Treatment of gastric leaks with a coated self-expanding stents after sleeve gastrectomy. Obes Surg 17(7): 866-872.

7. Serra C, Baltasar A, Pérez N, Bou R, Bengochea M, et al. (2006) Total gastrectomy for complications of the duodenal switch with reversal. Obes Surg 16(8): 1082-1086.

8. Baltasar A, Bou R, Bengochea M, Serra C, Cipagauta L (2007) Use of a Roux Limb to correct esophagogastric junction fistulas after sleeve gastrectomy. Obes Surg 17(10): $1408-1410$.

9. Marceau P, Biron S, Bourque RA, Potvin M, Hould FS, et al. (1993) Biliopancreatic diversion with a new type of gastrectomy. Obes Surg 3(1): 29-35.

10. Marchesini JB (2007) A safer and simpler technique for the duodenal switch (letter to the editor). Obes Surg 17(8): 1136.

11. Baltasar A, Serra C, Pérez N, Bou R, Bengochea M (2006) Re-sleeve gastrectomy. Obes Surg 16(11): 1535-1538.

\section{Your next submission with Juniper Publishers will reach you the below assets}

- Quality Editorial service

- Swift Peer Review

- Reprints availability

- E-prints Service

- Manuscript Podcast for convenient understanding

- Global attainment for your research

- Manuscript accessibility in different formats ( Pdf, E-pub, Full Text, Audio)

- Unceasing customer service

Track the below URL for one-step submission https://juniperpublishers.com/online-submission.php 